\title{
A Comparative Study on the Hemato-Biochemical and Immunological Effects of the Hexavalent FMD Vaccine Alone or in Combination with Trivalent FMD Vaccine in Cattle
}

\author{
Sherif M. Shawky ${ }^{1}$, Nahed S. Thabet ${ }^{2}$, Sahar H. Orabi ${ }^{3}$, Mohamed A. Nayel ${ }^{4}$ \\ ${ }^{1}$ Department of Physiology, Faculty of Veterinary Medicine, University of Sadat City, Egypt \\ ${ }^{2}$ Department of Clinical Pathology, Faculty of Veterinary Medicine, University of Sadat City, Egypt \\ ${ }^{3}$ Department of Biochemistry and Chemistry of Nutrition, Faculty of Veterinary Medicine, University of Sadat \\ City, Egypt \\ ${ }^{4}$ Department of Animal Medicine and Infectious Diseases, Faculty of Veterinary Medicine, University of Sadat \\ City, Egypt \\ Email: shsh00076@yahoo.com
}

Received 22 October 2015; accepted 27 December 2015; published 30 December 2015

Copyright (C) 2016 by authors and Scientific Research Publishing Inc.

This work is licensed under the Creative Commons Attribution International License (CC BY).

http://creativecommons.org/licenses/by/4.0/

(c) (i) Open Access

\section{Abstract}

Foot and mouth disease is the most contagious disease of mammals and has a great potential for causing severe economic loss in susceptible cloven-hoofed animals. Routine prophylactic vaccination in Egypt from 2012 till now has been conducted with Trivalent and/or hexavalent vaccine of MERIAL, against virus strains (0 manisa + 0-3039 + A Iran 05 + A Saudi 95 + Asia 1 + Sat2). This study aimed to evaluate the hemato-biochemical and immunological changes associated with the use of hexavalent vaccine alone or in combination with trivalent FMD vaccine. This study was carried out on 24 cattle divided into three groups eight cattle each. Group I served as control. Group II were selected from farms vaccinated with hexavalent FMD vaccine. Group III were selected from farms vaccinated with a combination of trivalent and hexavalent FMD vaccine. The results showed that both vaccinated groups showed a significant increase in total leukocytic count. Sera from hexavalent-trivalent vaccinated cattle demonstrated a significant increase in serum cortisol concentrations. Significant increase in serum activity of aspartate aminotransferase was recorded in animals vaccinated with a combination of hexavalent and trivalent vaccine. In addition, both regimes resulted in a significant increase in serum blood urea nitrogen compared to control. Both regimes induced a significant increase in serum levels of ceruloplasmin while phagocytic activity 
of neutrophils and phagocytic index was enhanced only by the hexavalent vaccine. Both vaccinated groups had significantly increased serum values of gamma globulins. These results suggested that hexavalent vaccine produced higher levels of safety and protective effects against FMD in cattle as compared to those produced by a combination of hexavalent and trivalent vaccines. It is also advisable to include the hexavalent vaccine within the program of obligatory and imperative vaccination against FMD.

\section{Keywords}

Hexavalent FMD Vaccine, Trivalent FMD Vaccine, Hemato-Biochemical, Immunological Effects, Cortisol

\section{Introduction}

Foot and mouth disease (FMD) is a highly contagious and fatal viral disease of cloven-hoofed animals. The disease is a high consequence livestock disease due to its potential for rapid spread, severe trade restrictions and the subsequent economic impacts that would result. Economic losses caused by FMD include reduction in production parameters such as decreases in milk production, weight gain, reproductive inefficiencies and death in young ruminants [1] [2].

Foot and mouth disease is caused by FMD virus (FMDV) which is a member of the family Picornaviridae. There are 7 serotypes of FMD virus; namely, O, A, C, SAT1, SAT2, SAT3, and Asia-1, which are immunologically distinct. But, even within each serotype, there are a large number of strains with their own antigenic characteristics, so there may be only partial cross-immunity between strains of the same serotype [3].

Since the 1950s, attention has been drawn to the economic importance of FMD in Egypt after several outbreaks of the disease affected cattle, buffaloes, sheep, goats and camels, with the predominant isolation of FMDV serotype O1 [4]. In February 2006, 6 outbreaks of FMDV occurred in Ismailia and 12 additional outbreaks in 7 other Egyptian governorates. The collected specimens from the diseased animals were tested for the isolation and identification of the FMDV and the laboratory results revealed the isolation of FMDV strain A [5] [6].

On 14 March 2012, thirteen outbreaks FMD were officially reported to the World Organization for Animal Health (OIE) in eight out of 27 governorates concentrated mainly in the Delta area and very few along the Nile in the southern parts of the country. The causative agent was identified as FMD-SAT2 virus [7]. Affected species included cattle and buffalo, and young buffaloes appeared to be the category of animals more severely affected. Mortalities in young stock might be high as a result of lack of maternal immunity. Livestock census data in Egypt estimated 6.3 million heads of buffalo and cattle in addition to 7.5 million heads of small ruminants (sheep and goats) were at risk [8]-[11]. FMD outbreaks are still evolving during 2013, 2014 and 2015.

Control of FMD becomes a challenge as soon as it infects a host as it replicates and spreads rapidly. Moreover, because of trade of live-animal and animal products all over the world, FMD control should be considered more and more in a global perspective [12].

Vaccination is of great importance in the protection of livestock in areas where FMD is endemic and continues to be used in conjunction with slaughter in the control of outbreaks in both FMD-free and FMD-endemic areas. Vaccination acts both to protect the individual animal and to provide herd immunity, by reducing the availability of susceptible animals [13]-[15]. The FMD vaccines that are currently used worldwide only consist of inactivated vaccines without introducing live vaccines. Inactivated FMD vaccines are commonly produced with as gel- or oil-adjuvant depending on the serotype [3] [16].

The policy of vaccination against FMD in Egypt is still implemented by initiate massive mandatory free charge vaccination programs applied every 4 months for dairy flocks and every 6 months for fattening animals using monovalent locally prepared standardized inactivated FMD vaccine O1 (Veterinary Serum and Vaccine Research \& Institute "VSVRI", Abassia, Cairo, Egypt). But from April 2006 vaccination started by using bivalent vaccine (A Egy 2009, O Sharquia) instead of monovalent vaccine strain (O) which were used previously. After the serotype SAT2 outbreaks in 2012, Trivalent (A Egy 2009, O Sharquia and SAT2/2012) and/or the 
hexavalent aftovaxpur vaccine of MERIAL, against virus strains (O manisa + O-3039 + A Iran 05 + A Saudi 95 + Asia $1+$ Sat2) were in use till now.

But based on field observations, it was found that farms vaccinated with the hexavalent vaccine resisted the re-attack while farms vaccinated with trivalent vaccine alone or in combination with hexavalent vaccine were reattached with FMD. Therefore this study aimed to compare the hemato-biochemical and immunological changes associated with the use of the vaccination regimes, hexavalent and the combination of trivalent and hexavalent FMD vaccines.

\section{Materials and Methods}

\subsection{Experimental Animals}

This study was carried out on 24 cattle. The selected animals were divided into three groups eight cattle each. Animals in group I were unvaccinated and served as controls. Animals in group II were selected from farms vaccinated with hexavalent FMD vaccine (O manisa + O-3039 + A Iran 05 + A Saudi 95 + Asia $1+$ Sat2). Finally, animals in group III were selected from farms vaccinated with a combination of trivalent and hexavalent FMD vaccine. All vaccines were locally produced at the Veterinary Serum and Vaccine Research Institute "VSVRI", Abassia, Cairo, Egypt).

\subsection{Blood Samples}

Blood samples were collected from jugular veins of control group in addition to vaccinated animals 8 week post vaccination. The blood sample was divided into three parts. The first part $(1 \mathrm{ml})$ was collected on disodium ethylene diamine tetracetic acid (EDTA) for hemogram. The second part $(1 \mathrm{ml})$ was collected on heparin (20 $\mathrm{IU} / \mathrm{ml}$ ) for evaluating the phagocytic activity of neutrophils. The third part $(5 \mathrm{ml})$ was placed in a plain centrifuge tubes for separation of serum and serum samples were stored at $-20^{\circ} \mathrm{C}$ until used for subsequent biochemical and immunological analysis.

\subsection{Analytical Methods}

\subsubsection{Hematological Assays}

The evaluated hematological parameters in this study included estimation of red blood cell count (RBCs), hemoglobin concentration (Hb), packed cell volume (PCV) and total (TLC) and differential leukocytic counts. These parameters were done according to the routine hematological procedures as described by Feldman et al. [15].

\subsubsection{Serum Biochemical Assays}

Serum samples were evaluated for the enzymatic activities of alanine aminotransferase (ALT) and aspartate aminotransferase (AST) in addition to serum concentrations of blood urea nitrogen (BUN) and creatinine. These parameters were determined spectrophotometric method using commercially available test kits supplied by Biomed diagnostics (Germany) according to the manufacturer's instructions. Serum levels of cortisol were detected using ELISA technique and test kits supplied by Hellabio biokits (USA).

\subsection{Immunological Studies}

Phagocytic activity of polymorphonuclear cells using Candida albicans and phagocytic index were performed according to the method described by Ortega et al. [17]. Serum values of ceruloplasmin (CP) were measured by spectrophotometric method and using commercial kits of Boehringer Ingelheim (Germany). Serum protein electrophoretic fractionation profile was carried out by a Polyacrylamide Gel Electrophoresis using commercial kits of Cobasintegra (Roche, Germany) and following the manufacturer's instructions.

\subsection{Statistical Analysis}

Data were presented as mean \pm standard error (SE) and were subjected to statistical analysis using one-way analysis of variance (ANOVA) according to Snedecor and Cochran [18]. Post hoc differences between means were tested by a multiple comparison Duncan test. Differences at $\mathrm{p}<0.05$ were considered significant. Correla- 
tion between selected parameters was done using pearsons' correlation test.

\section{Results}

\subsection{Hematological Parameters}

The data shown in Table 1 clarified that there were no significant differences in red cell count, Hb concentrations and PCV in both vaccinated and non-vaccinated groups. While both vaccination regimes resulted in significant $(\mathrm{P}<0.05)$ elevations in TLC, neutrophil and lymphocyte counts in comparison to the control group.

\subsection{Biochemical Parameters}

The results of biochemical parameters have been summarized in Table 2. The mean values of serum enzymatic activity of AST showed a significant increase $(\mathrm{P}<0.05)$ in group vaccinated with the trivalent-hexavalent combined vaccine compared with control and hexavalent-vaccinated groups. No significant differences were seen in serum ALT activity between different groups. Serum BUN concentrations showed a significant $(\mathrm{P}<0.05)$ increase in the vaccinated animals while serum creatinine values did not show significant alterations (Table 2). The mean values of serum cortisol concentrations were significantly higher in the group given a combination of trivalent and hexavalent vaccine as compared to other groups (Table 3).

\subsection{Immunological Parameters}

Compared to control and trivalent-hexavalent groups, animals vaccinated with hexavalent FMD vaccine demonstrated a significant increase in phagocytic activity and phagocytic index (Table 4). On the other hand, both

Table 1. The effects of hexavalent or hexavalent-trivalent combined vaccines on hematological parameters of cattle. Values are means $\pm \mathrm{SE}$.

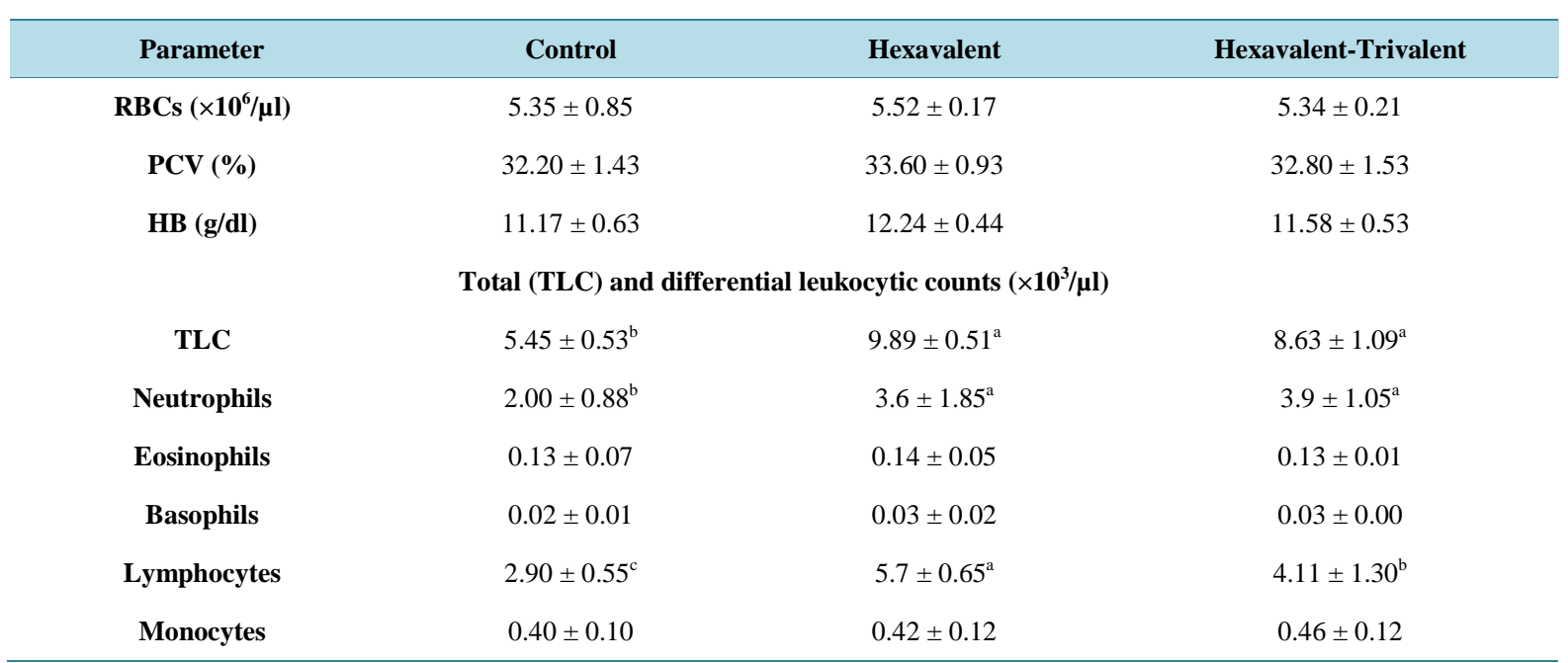

Different letters in same raw show significant difference at $\mathrm{P}<0.05$.

Table 2. The effects of hexavalent or hexavalent-trivalent FMD combined vaccines on some serum biochemical parameters of cattle. Values are means \pm SE.

\begin{tabular}{cccc}
\hline Parameter & Control & Hexavalent & Hexavalent-Trivalent \\
\hline AST (IU/L) & $68.60 \pm 7.43^{\mathrm{b}}$ & $68.26 \pm 3.14^{\mathrm{b}}$ & $112.36 \pm 9.21^{\mathrm{a}}$ \\
ALT (IU/L) & $32.67 \pm 2.54$ & $33.25 \pm 2.02$ & $28.58 \pm 1.54$ \\
BUN (mg/dl) & $34.40 \pm 1.87^{\mathrm{b}}$ & $41.60 \pm 1.72^{\mathrm{a}}$ & $44.85 \pm 1.27^{\mathrm{a}}$ \\
Creatinine (mg/d) & $0.91 \pm 0.06$ & $0.94 \pm 0.07$ & $0.82 \pm 0.04$ \\
\hline
\end{tabular}

Different letters in same raw show significant difference at $\mathrm{P}<0.05$. 
Table 3. The effects of hexavalent or hexavalent-trivalent combined FMD vaccines on serum cortisol levels of cattle. Values are means $\pm \mathrm{SE}$.

\begin{tabular}{cccc}
\hline Parameter & Control & Hexavalent & Hexavalent-Trivalent \\
\hline Cortisol $(\mu \mathrm{g} / \mathbf{d l})$ & $1.14 \pm 0.34^{\mathrm{b}}$ & $1.10 \pm 0.07^{\mathrm{b}}$ & $3.35 \pm 0.36^{\mathrm{a}}$ \\
\hline
\end{tabular}

Different letters in same raw show significant difference at $\mathrm{P}<0.05$.

Table 4. The effects of hexavalent or hexavalent-trivalent combined FMD vaccines on phagocytic activity, phagocytic index and serum levels of ceruloplasmin of cattle. Values are means $\pm \mathrm{SE}$.

\begin{tabular}{cccc}
\hline Parameter & Control & Hexavalent & Hexavalent-Trivalent \\
\hline Phagocytic activity (\%) & $63.60 \pm 0.9^{\mathrm{b}}$ & $70.20 \pm 0.86^{\mathrm{a}}$ & $61.40 \pm 0.93^{\mathrm{b}}$ \\
Phagocytic index & $2.61 \pm 0.11^{\mathrm{b}}$ & $3.22 \pm 0.11^{\mathrm{a}}$ & $2.27 \pm 0.12^{\mathrm{b}}$ \\
CP (mg/dl) & $7.85 \pm 0.89^{\mathrm{b}}$ & $8.15 \pm 0.27^{\mathrm{b}}$ & $12.75 \pm 2.13^{\mathrm{a}}$ \\
\hline
\end{tabular}

Different letters in same raw show significant difference at $\mathrm{P}<0.05$.

vaccinated groups elicited an increase in serum ceruloplasmin levels with greater significant values were recorded in the trivalent-hexavalent vaccinated animals.

\subsection{Serum Protein Electrophoretic Fractionation}

Serum protein electrophoretic fractionation revealed a significant increase $(\mathrm{P}<0.05)$ in total proteins and total globulins (Tg) in animals vaccinated with the hexavalent vaccine compared to control and trivalent-hexavalent combined FMD vaccine groups (Table 5). Serum concentrations of alpha 2 globulin $(\alpha 2$-g) showed a significant increase in both treated groups while the increase in beta globulins $(\beta$-g) was marked in the hexavalent group. Both vaccinated groups demonstrated significant increase in serum levels of gamma globulins $(\gamma-\mathrm{g})$ with the higher values were recorded for the animals receiving hexavalent vaccine alone (Table 5).

\subsection{Correlation between Cortisol and the Selected Parameters in the Vaccinated Groups}

As shown in Table 6, correlation between serum levels of cortisol and the selected parameters in the vaccinated groups indicated that in second group vaccinated with hexavalent vaccine alone there was a significant positive correlation between cortisol and BUN and $\beta$-g. In animals given the hexavalent-trivalent combined vaccine there was a significant positive correlation between cortisol and neutrophil, AST, BUN, phagocytic activity, phagocytic index, ceruloplasmin and $\alpha 2$-g while, a significant negative correlation was found between cortisol and lymphocyte, total protein and $\gamma$-g (Table 6).

Table 5. The effects of hexavalent or hexavalent-trivalent combined FMD vaccines on serum protein (total and electrophoretic) pattern of cattle. Values are means $\pm \mathrm{SE}$.

\begin{tabular}{cccc}
\hline Parameter (g/dl) & Control & Hexavalent & Hexavalent-Trivalent \\
\hline Total protein & $6.19 \pm 0.29^{\mathrm{b}}$ & $8.18 \pm 0.19^{\mathrm{a}}$ & $7.09 \pm 0.74^{\mathrm{ab}}$ \\
Albumin & $3.60 \pm 0.12$ & $3.24 \pm 0.09$ & $3.70 \pm 0.16$ \\
Total globulin & $2.59 \pm 0.19^{\mathrm{b}}$ & $4.94 \pm 0.13^{\mathrm{a}}$ & $3.39 \pm 0.66^{\mathrm{b}}$ \\
Alpha1 globulin & $0.56 \pm 0.07$ & $0.41 \pm 0.12$ & $0.41 \pm 0.06$ \\
Alpha 2 globulin & $0.46 \pm 0.04^{\mathrm{b}}$ & $0.61 \pm 0.03^{\mathrm{a}}$ & $0.65 \pm 0.02^{\mathrm{a}}$ \\
Beta globulin & $0.70 \pm 0.19^{\mathrm{b}}$ & $1.44 \pm 0.05^{\mathrm{a}}$ & $0.99 \pm 0.15^{\mathrm{ab}}$ \\
Gamma globulin & $0.87 \pm 0.21^{\mathrm{c}}$ & $2.48 \pm 0.23^{\mathrm{a}}$ & $1.34 \pm 0.36^{\mathrm{b}}$
\end{tabular}

Different letters in same raw show significant difference at $\mathrm{P}<0.05$. 
Table 6. The correlation between serum levels of cortisol and the selected parameters in the vaccinated groups (Pearson's correlation test).

\begin{tabular}{ccc}
\hline Parameter & Hexavalent & Hexavalent-Trivalent \\
\hline Total leukocytic count & 0.504 & 0.703 \\
Neutrophil & 0.500 & $0.882^{*}$ \\
Lymphocyte & -0.556 & $-1.000^{* *}$ \\
AST & 0.693 & $0.899^{*}$ \\
BUN & $0.871^{*}$ & $1.000^{* *}$ \\
Phagocytic activity & 0.756 & $0.902^{*}$ \\
Phagocytic index & 0.500 & $0.997^{* *}$ \\
Ceruloplasmin & 0.412 & $1.000^{* *}$ \\
Total protein & -0.264 & $-0.945^{*}$ \\
Total globulin & -0.446 & -0.676 \\
Alpha 2-globulin & 0.500 & $0.997^{* *}$ \\
Beta-globulin & $0.891^{*}$ & 0.432 \\
Gamma-globulin & -0.476 & $-0.902^{*}$ \\
\hline
\end{tabular}

${ }^{*}$ Correlation is significant at the 0.05 level; ${ }^{* *}$ Correlation is significant at the 0.01 level.

\section{Discussion}

Foot and mouth disease is the most contagious disease of mammals and has a great potential for causing severe economic loss in susceptible cloven-hoofed animals [14]. The disease has severe implications for animal farming, since it is highly infectious and can be spread by infected animals through aerosols, through contact with contaminated farming equipment, vehicles, clothing, or feed, and by domestic and wild predators [19]. Its containment demands considerable efforts in vaccination, strict monitoring, trade restrictions, and quarantines, and occasionally the killing of animals [20]. Vaccination is still one of the most important policies for the control and prevention of FMD. A sound decision on vaccination can be made only if there is sufficient scientific knowledge on the effectiveness of vaccination in eliminating the virus from the population [19]. Control of FMD is usually a national responsibility and, in many countries, the vaccine may be used only under the control of the Competent Authority.

Egypt has been considered to be endemic by A and O FMD strains until 2012 [9] [10] [21]. During 2012/2013, a new extensive FMD outbreak struck Egypt and killed more than 4600 animals and laboratory investigations supported the cause to be the serotype SAT2 [7] [21] [22]. From that time and till now, SAT2 clinically has manifested itself by causing severe clinical disease in cattle and buffalo and no other serotypes were detected [23]. In addition there was a failure to detect serotypes $\mathrm{A}$ and $\mathrm{O}$ suggesting that these serotypes were under control by vaccination in Egypt [24]. Because of the great economic importance of this disease there is increasing an interest for the control and prevention of FMD in the future as well as there is an increased awareness of the owners about the necessities of the vaccination campaigns. Routine prophylactic vaccination in Egypt from 2012 and till now has been conducted with Trivalent (A Egy 2009, O Sharquia and SAT2/2012) and/or hexavalent vaccine of MERIAL, against virus strains (O manisa + O-3039 + A Iran 05 + A Saudi 95 + Asia 1 + Sat2). But surprisingly field experience with vaccination against FMD revealed that farms vaccinated with the hexavalent vaccine showed great protection against FMD while some farms used a combination of hexavalent and trivalent vaccines were reattached with FMD, a case which required inevitable explanation and clarification to find out possible underlying causes. Although the immunological effects of any vaccine are considered the most important factor to judge the efficiency of the immunization, their possible impact on the functional states of other body systems and general health situation cannot be ignored as it can provide an explanation for certain ambiguous and incomprehensible conditions. Therefore, a particular focus of this work has been to consider the impact of the se- 
lected vaccination regimes on some hematological and biochemical parameters. In this respect, the data of the present study showed that hexavalent-trivalent vaccinated cattle demonstrated a significant increase in serum cortisol concentrations implicating strong stress response in this group. In cattle, many conditions have been considered to be stressors such as vaccination, weaning, mixing and transportation and have been shown to lead to increased blood concentrations of cortisol [25].

Cortisol has been termed "the stress hormone" because it's also secreted in higher levels during the body's 'fight or flight' response to stress and body's reaction to a challenge and is responsible for several stress-related changes in the body [26] [27]. Although the present work was not able to identify the factors responsible for the stress response in the combined vaccine group compared to the hexavalent vaccine group, the reason could be probably related to the high antigenic dose in the combined vaccine which unexpectedly served as a kind of stress on the animal. Stress of vaccination in some cases has been shown to trigger a latent infection into becoming a clinical disease [28]. Other environmental and managerial conditions cannot be also excluded.

The results of hemogram revealed a significant increase in total leukocytic count in both vaccinated groups which could be explained by neutrophilia and lymphocytosis. Neutrophil is the most important phagocytic cell which participates in the innate immune response, also known as the nonspecific immune response [29]. Lymphocytosis is the result of enhancement of the B cell function for antibody formation as indicated in the present study by increased gamma globulins [30].

In group receiving the combined FMD vaccine, neutrophilia could be also attributed to the stress response as a result of endogenous release of cortisol which have major role in regulating circulating concentration of leukocytes [31]. This is further supported by the significant positive correlation between serum cortisol concentrations and neutrophil in this group. Hexavalent vaccinated group demonstrated pronounced lymphocytosis suggesting a stronger humoral immune response. However, in the group receiving the combined vaccine, the lymphocyte response was significantly lower than hexavalent vaccine group which could also be attributed to the significant stress response in the combined vaccine group. Cortisol excess is most commonly associated with redistribution of lymphocytes and thus lymphopenia. Therefore probably the combination of the two impacts on blood lymphocytes might lead to lymphocytosis to be much lower in the combined vaccine group compared to the hexavalent vaccine group.

Monitoring the serum values of some biochemical parameters revealed a significant increase in serum activity of AST in animals vaccinated with a combination of hexavalent and trivalent vaccine. Although AST is not hepatic specific it is widely used in cattle to detect liver disease in spite of its lack of specificity [31]. So the increase in serum activity of AST may suggest some degree of hepatic dysfunction. Slight elevation in serum AST may be associated with glucocorticoid excess so stress can induce increased serum AST activity. Consequently, this increase could be attributed in part to increased cortisol levels as evidenced by the significant positive correlation between cortisol and AST in the combined vaccine group [32].

In consistence with the findings of Ognean et al. [33], this work has shown that there was a significant increase in serum values of blood urea nitrogen in both vaccinated group in compare with control while no significant changes were recorded in the levels of creatinine excluding the possibility of presence of renal dysfunction.BUN can elevate in conditions other than primary renal disease, especially when large amounts of protein are available to be processed with increased protein breakdown larger amounts of urea will be made. Also in ruminants, urea excretion by the kidney is dependent on nitrogen balance and nitrogen content in diet [34]. Increased protein catabolism can also be seen in glucocorticoids due to increased hepatic synthesis of urea so stress can elicit a marked increase in BUN.

Generally, immune response against FMDV is evaluated on the basis of humoral immune response i.e. antibody titres. However, it has also been suggested that that innate immune defenses, could play an important role in the protection induced by FMDV vaccines [35] [36]. An immunogen is a substance that is able to provoke a humoral and/or cell-mediated immune response. It first initiates an innate immune response, which causes the activation of the adaptive immune response [37].

In this study animals vaccinated with the hexavalent vaccine demonstrated a significant increases in both phagocytic activity and phagocytic index of neutrophils. These results may be attributed to stimulation of the innate immune response occurred post vaccination. Leukocyte chemotaxis has been modulated by FMD vaccine resulting in increased chemotactic activity in the blood, and mobilization of phagocytic cells from the bone marrow probably to the site of injection. Therefore, following FMD vaccination, phagocytic function would be enhanced, both in terms of the individual cell recruited and the increased number of migratory leucocytes [35]. 
Acute phase proteins are considered integral to the non-specific innate immune response and can be valuable quantitative markers and useful indicators for stress and disease. Their serum concentrations change in animals subjected to external or internal challenges such as infection or stress [38]. Ceruloplasmin is a copper-dependent acute phase reaction protein which belongs to alpha globulins and has been reported to increase in response to the tissue damage and inflammation [39]. Significant elevation in serum ceruloplasmin was observed in both vaccinated groups indicating that the vaccines promote a systemic acute phase response [40].

In the combined vaccine group, the values of ceruloplasmin levels were significantly higher than in animals injected with the hexavalent vaccine alone which could be related to increased serum cortisol as indicated by the significant positive correlation between ceruloplasmin and cortisol in the combined vaccine group. Cortisol was found to stimulate many copper enzymes probably to increase copper availability for immune purposes [41]. Lomborg et al. [42] reported that stressors such as weaning, mixing and transportation with the resultant increase in cortisol have been shown to lead to increased blood concentrations of acute phase proteins. In calves, acute phase proteins have been used as biomarkers for the stress status of ruminants both experimentally and in field studies [43]. These findings also are in consistency with the results of $\alpha 2$ and $\beta$ globulins presented in this study which showed a significant increase as most important proteins of the acute-phase response are in $\alpha$ and $\beta$ globulins [31] [32].

Humoral immunity is known to be the most influential factor in preventing FMD and have superior antibody formation [2] [44]. As a result, the vaccines that have recently been used worldwide are improving in terms of the level of immunity conferred and securing long lasting antibody [2]. In this respect, the current findings of serum protein electrophoresis revealed a significant increase in serum concentrations of total proteins and total globulins in the hexavalent vaccine group which could be attributed to hypergammaglobulinemia.

Serum values of gamma globulins were significantly increased in both groups compared to control. Specifically, hexavalent-vaccinated animals demonstrated significantly higher values of gamma globulins compared to animals receiving the combined vaccines reflecting a stronger humoral immune response and greater protection provided with hexavalent vaccine for cattle in the face of FMD. An FMD vaccine stimulates a predominantly humoral immune response in the vaccinated animal and, in cattle, there was a good correlation between antibody level and protection against live virus challenge by the same strain of FMD virus from which the vaccine was produced [30]. It is generally accepted that a higher concentration of serum immunoglobulins provide more protection against the diseases.

The immune response to an initial vaccination depends on the dose of antigen used. The hexavalent-trivalent combined vaccine have numerous viruses as well as other ingredients in them. Exceptions to this might include an increase in antibody production and higher degree of immune response [2] [45]. This was not the case in this study and the levels of gamma globulins were significantly lower in this group compared to the hexavalent vaccine alone probably due to the strong stress response reported in animals administered the combined FMD vaccine. Cortisol and the stress response is known to compromise or suppress the activity of the immune system by inhibiting lymphocyte populations, lymphocyte proliferation, antibody production and reactivation of latent infections [43] [46]. The activation of the stress system and resulting increase in cortisol was believed to be a protective mechanism which prevents an over activation of the inflammatory response resulting from over activity of the B-cell-mediated antibody response [26] [27].

In another words, despite the high antigenic dose in the FMD combined vaccine, antibody production was hampered by the strong stress response in this group and the degree of increase in immunoglobulins was not able to provide sufficient protection against the disease.

\section{Conclusion}

In conclusion, monitoring of the two vaccination regimes revealed that hexavalent vaccine produced higher levels of safety and protective effects against FMD in cattle as compared to those produced by a combination of hexavalent and trivalent vaccines. The stress response of vaccination is likely the key factor in the failure of the combined vaccine to provide the sufficient protection due to impairing the immune response. However, further work is required to elucidate the possible role of other environmental and managerial factors. It is also advisable to include the hexavalent vaccine within the program of obligatory and imperative vaccination against FMD. This can be assisted by ongoing surveillance regarding which serotypes and strains of FMDV are in circulation. 


\section{References}

[1] Radostits, O.M., Gay, C.C., Blood, D.C. and Hinchkiff, K.W. (2000) A Text Book of Veterinary Medicine. 9th Edition, ELBS and Baillier Tindall, London, 563-618.

[2] Park, J. (2013) Requirements for Improved Vaccines against Foot-and-Mouth Disease Epidemics. Clinical and Experimental Vaccine Research, 2, 8-18. http://dx.doi.org/10.7774/cevr.2013.2.1.8

[3] Doel, T.R. (2003) FMD Vaccines. Virus Research, 91, 81-99. http://dx.doi.org/10.1016/S0168-1702(02)00261-7

[4] Aidaros, H.A. (2002) Regional Status and Approaches to Control and Eradication of FMD in the Middle East and North Africa. Rev. sci. tech. Off. int. Epiz., 21, 451-458.

[5] Knowles, N.J. and Samuel, A.R. (2003) Molecular Epidemiology of Foot-and-Mouth Disease Virus. Virus Research, 91, 65-80. http://dx.doi.org/10.1016/S0168-1702(02)00260-5

[6] Abd El-Rahman, A.O., Farag, M.A., El-Kilany, S., Eman, M.A, Abo Yazed, M. and Zeidan, S. (2006) Isolation and Identification of FMDV During an Outbreak of 2006 in Egypt. Kafr EL-Sheikh Vet. Med. J., 4, 451-464.

[7] Zaher, K.S. and Ahmed, W.M. (2014) The Role of Foot and Mouth Disease Outbreak in 2012 on Egyptian Small Ruminants and Pigs. Global Veterinaria, 12, 583-587.

[8] Ghoneim, N.H., Abdel-Karim, A.K.M., El-Shehawy, L. and AbdelMoein, K.A. (2010) FMD in Animals in Sharkia Governorate, Egypt. Transboundary and Emerging Diseases, 57, 19-21.

[9] Ahmed, H.A., Salem, S.A., Habashi, A.R., Arafa, A.A., Aggour, M.G., Salem, G.H., Gaber, A.S., Selem, O., Abdelkader, S.H., Knowles, N.J., Madi, M., Valdazo-González, B., Wadsworth, J., Hutchings, G.H., Mioulet, V., Hammond, J.M. and King, D.P. (2012) Emergence of Foot-and-Mouth Disease Virus SAT 2 in Egypt during 2012. Transboundary and Emerging Diseases, 59, 476-481. http://dx.doi.org/10.1111/tbed.12015

[10] Valdazo-González, B., Knowles, N.J., Hammond, J.M. and King, D.P. (2012) Genome Sequences of SAT 2 Footand-Mouth Disease Viruses from Egypt and Palestinian Autonomous Territories (Gaza Strip). Journal of Virology, 86, 8901-8902. http://dx.doi.org/10.1128/JVI.01231-12

[11] Hall, M.D., Knowles, N.J., Wadsworth, J., Rambaut, A. and Woolhouse, M.E.J. (2013) Reconstructing Geographical Movements and Host Species Transitions of Foot-and-Mouth Disease Virus Serotype SAT 2. mBio, 4, e00591-13. http://dx.doi.org/10.1128/mBio.00591-13

[12] Kahn, S., Geale, D.W., Kitching, P.R., Bouffard, A., Allard, D.G. and Duncan, J.R. (2002) Vaccination against Footand-Mouth Disease: The Implications for Canada. Canadian Veterinary Journal, 43, 349-354.

[13] Sutmoller, P. and Casas Olascoaga, R. (2003) The Risks Posed by the Importation of Animals Vaccinated against Foot and Mouth Disease and Products Derived from Vaccinated Animals: A Review. Revue Scientifique et Technique (International Office of Epizootics), 22, 823-835.

[14] Lu, Z. (2007) Development and Validation of a 3ABC Indirect ELISA for Differentiation of Foot-and-Mouth Disease Virus Infected from Vaccinated Animals. Veterinary Microbiology, 125, 157-169. http://dx.doi.org/10.1016/j.vetmic.2007.05.017

[15] Feldman, B.F., Zinkl, J.G. and Jain, N.C. (2000) Schalms Veterinary Haematology. 5th Edition, Williams and Wilkins, Philadelphia, 21-100.

[16] Sáiza, M., Núñez, J.I., Jimenez-Clavero, M.A., Baranowski, E. and Sobrino, F. (2002) Foot-and-Mouth Disease Virus: Biology and Prospects for Disease Control. Microbes and Infection, 4, 1183-1192. http://dx.doi.org/10.1016/S1286-4579(02)01644-1

[17] Ortega, E., Rodriges, M.J., Barriga, C. and Forner, M.A. (1996) Corticosterone, Prolactin and Thyroid Hormones as Hormonal Mediators of Stimulated Phagocytic Capacity of Peritoneal Macrophages after High-Intensity Exercise. International Journal of Sports Medicine, 17, 149-155. http://dx.doi.org/10.1055/s-2007-972824

[18] Snedecor, G.W. and Cochran, W.G. (1980) Statistical Methods. 7th Edition, Iowa State University Press, Ames.

[19] Orsel, K. and Bouma, A. (2009) The Effect of Foot-and-Mouth Disease (FMD) Vaccination on Virus Transmission and the Significance for the Field. Canadian Veterinary Journal, 50, 1059-1063.

[20] Knight-Jones, T.J.D. and Rushton, J. (2013) The Economic Impacts of Foot and Mouth Disease-What Are They, How Big Are They and Where Do They Occur? Preventive Veterinary Medicine, 112, 161-173. http://dx.doi.org/10.1016/j.prevetmed.2013.07.013

[21] FAO (2012) Foot-and-Mouth Disease Caused by Serotype SAT2 in Egypt and Libya: A Regional Concern for Animal Health in North Africa and the Middle East. EMPRES Watch, 25.

[22] El-Shehawy, L.I., Abu-Elnaga, H.I., Rizk, S.A., El-Kreem, A.S.A., Mohamed, A.A. and Fawzy, H.G. (2014) Molecular Differentiation and Phylogenetic Analysis of the Egyptian Foot-and-Mouth Disease Virus SAT2. Archives of Virology, 159, 437-443. http://dx.doi.org/10.1007/s00705-013-1825-1 
[23] Elhaig, M.M. and Elsheer, M.N. (2014) Molecular Investigation of Foot-and-Mouth Disease Virus in Domestic Bovids from Gharbia, Egypt. Tropical Animal Health and Production, 46, 1455-1462. http://dx.doi.org/10.1007/s11250-014-0665-7

[24] Kandeil, A., El-Shesheny, R., Kayali, G., Moatasim, Y., Bagato, O., Darwish, M., Gaffar, A., Younes, A., Farag, T., Kutkat, M.A. and Ali, M.A. (2013) Characterization of the Recent Outbreak of Foot-and-Mouth Disease Virus Serotype SAT2 in Egypt. Archives of Virology, 158, 619-627. http://dx.doi.org/10.1007/s00705-012-1529-y

[25] Kim, M., Yang, J., Upadhaya, S.D., Lee, H., Yun, C. and Ha, J.K. (2011) The Stress of Weaning Influences Serum Levels of Acute-Phase Proteins, Iron-Binding Proteins, Inflammatory Cytokines, Cortisol, and Leukocyte Subsets in Holstein Calves. Journal of Veterinary Science, 12, 151-157. http://dx.doi.org/10.4142/jvs.2011.12.2.151

[26] Dhabhar, F.S. (2009) Enhancing versus Suppressive Effects of Stress on Immune Function: Implications for Immunoprotection and Immunopathology. Neuroimmunomodulation, 16, 300-317. http://dx.doi.org/10.1159/000216188

[27] Martin, L.B. (2009) Stress and Immunity in Wild Vertebrates: Timing Is Everything. General and Comparative Endocrinology, 163, 70-76. http://dx.doi.org/10.1016/j.ygcen.2009.03.008

[28] Max’s House (2015) Max’s House Feline Health \& Behavior Monthly Newsletter Vaccination Protocols in Cats. http://maxshouse.com/vaccine_protocols.htm.

[29] Kumar, V. and Sharma, A. (2010) Neutrophils: Cinderella of Innate Immune System. International Immunopharmacology, 10, 1325-1334. http://dx.doi.org/10.1016/j.intimp.2010.08.012

[30] Brown, F. (1999) Foot-and-Mouth Disease and Beyond: Vaccine Design, Past, Present and Future. In: Calisher, C.H. and Horzinek, M.C., Eds., 100 Years of Virology, Archives of Virology. Supplementa, Vol. 15, Springer, Vienna, 179188. http://dx.doi.org/10.1007/978-3-7091-6425-9_13

[31] Duncan, J.R., Prasse, K.W. and Mahaffey, E.A. (1994) Veterinary Laboratory Medicine: Clinical Pathology. 3rd Edition, Iowa State University Press, Ames.

[32] Kaneko, J.J., Harvey, J.W. and Bruss, M.L. (1997) Clinical Biochemistry of Domestic Animals. 5th Edition, Academic Press, San Diego.

[33] Ognean, L., Chiurciu, C., Zavoiu, F., Cernea, C., Cernea, M., Todoran, C., Moldovan, M. and Trinca, S. (2010) The Relevance of Some Physiological Parameters in Evaluating the Safety of Two Vaccine Formulation against Contagious Agalaxia in Goats. Bulletin of University of Agricultural Sciences and Veterinary Medicine Cluj-Napoca. Agriculture, 67, 166-178.

[34] Kohn, R.A., Dinneen, M.M. and Russek-Cohen, E. (2005) Using Blood Urea Nitrogen to Predict Nitrogen Excretion and Efficiency of Nitrogen Utilization in Cattle, Sheep, Goats, Horses, Pigs, and Rats. Journal of Animal Science, 83, 879-889.

[35] Rigdena, R.C., Carrascoa, C.P., Barnettb, P.V., Summerfielda, A. and McCullough, K.C. (2003) Innate Immune Responses Following Emergency Vaccination against Foot-and-Mouth Disease Virus in Pigs. Vaccine, 21, 1466-1477. http://dx.doi.org/10.1016/S0264-410X(02)00663-1

[36] Chhabra, R., Sharma, R. and Kakker, N.K. (2004) Comparative Immunogenecity of Foot and Mouth Disease Virus Antigens in FMD-Haemorrhagic Septicaemia Combined Vaccine and FMD Vaccine Alone in Buffalo Calves. Indian Journal of Experimental Biology, 42, 259-264.

[37] Vibha, J., Degroot, A., Cousens, L., Awwad, M., Kropshofer, H. and Wakshull, E. (2013) T-Cell Dependent Immunogenicity of Protein Therapeutics: Preclinical Assessment and Mitigation. Clinical Immunology, 149, 534-555. http://dx.doi.org/10.1016/j.clim.2013.09.006

[38] Ceron, J.J., Eckersall, P.D. and Martinez-Subiela, S. (2005) Acute Phase Proteins in Dogs and Cats: Current Knowledge and Future Perspectives. Veterinary Clinical Pathology, 34, 85-99. http://dx.doi.org/10.1111/j.1939-165X.2005.tb00019.x

[39] Gursel, F.E., Durak, M.H. and Altiner, A. (2010) Serum Ceruloplasmin Levels in Ewes Fed Deficient-Energy during Late Pregnancy. Journal of Animal and Veterinary Advances, 9, 820-825. http://dx.doi.org/10.3923/javaa.2010.820.825

[40] Arthington, J.D., Cooke, R.F., Maddock, T.D., Araujo, D.B., Moriel, P., Dilorenzo, N. and Lamb, G.C. (2013) Effects of Vaccination on the Acute-Phase Protein Response and Measures of Performance in Growing Beef Calves. Journal of Animal Science, 91, 1831-1837. http://dx.doi.org/10.2527/jas.2012-5724

[41] Weber, C.E. (1984) Copper Response to Rheumatoid Arthritis. Medical Hypotheses, 15, 333-348. http://dx.doi.org/10.1016/0306-9877(84)90150-6

[42] Lomborg, S.R., Nielsen, L.R., Heegaard, P.M.H. and Jacobsen, S. (2008) Acute Phase Proteins in Cattle after Exposure to Complex Stress. Veterinary Research Communications, 32, 575-582. http://dx.doi.org/10.1007/s11259-008-9057-7

[43] Yun, C., Wynn, P. and Ha, J.K. (2014) Stress, Acute Phase Proteins and Immune Modulation in Calves. Animal Production Science, 54, 1561-1568. http://dx.doi.org/10.1071/AN14441 
[44] Doel, T.R. (1996) Natural and Vaccine-Induced Immunity to Foot and Mouth Disease: The Prospects for Improved Vaccines. Revue Scientifique et Technique, 15, 883-911.

[45] Schley, D., Tanaka, R.J., Leungchavaphongse, K., Shahrezaei, V., Ward, J. and Grant, C. (2012) Modelling the Influence of Foot-and-Mouth Disease Vaccine Antigen Stability and Dose on the Bovine Immune Response. PLoS ONE, 7, e30435. http://dx.doi.org/10.1371/journal.pone.0030435

[46] Marketon, J.I. and Glaser, R. (2008) Stress Hormones and Immune Function. Cellular Immunology, 252, 16-26. http://dx.doi.org/10.1016/j.cellimm.2007.09.006 